\title{
TEORIAS JURÍDICAS ACERCA DO INÍCIO DA VIDA HUMANA
}

\section{Raphael Mendonça Costa Cildo Giolo Júnior}

\section{RESUMO}

Este estudo apresenta as diversas teorias acerca do início da vida humana, com o intuito de definir esse início conforme o ordenamento jurídico brasileiro. Isto porque se faz necessário conceituar primeiramente o que é vida, para somente então ser possível questionar o que é o homem. Além de demonstrar as diversas teorias formuladas acerca do tema, serão apresentadas as principais teorias jurídicas sobre o início da vida humana, e será feita uma visão crítica de cada uma, concluindo que é da essência do ser humano a sua capacidade de raciocinar, sendo assim, a sua vida se inicia com as primeiras atividades cerebrais. A teoria eleita será sustentada pela definição de morte trazida pela lei de transplante de órgãos, e será demonstrado que a teoria defendida está de acordo com os julgados do Supremo Tribunal Federal nas ocasiões em que se manifestou acerca do tema.

Palavras-chaves: Início da vida humana. Essência humana. Teoria Concepcionista. Teoria da Nidação. 


\section{INTRODUÇÃO}

O marco inicial da vida humana não é um tema pacífico, nem entre estudiosos da mesma área, na qual juristas discordam uns dos outros e o mesmo ocorre com filósofos, cientistas e religiosos.

Em busca deste conceito, foram tecidas inúmeras teses, tentando estabelecer o ponto definitivo para o início da vida e é importante que o ordenamento jurídico brasileiro adote um destes posicionamentos, para proporcionar maior segurança jurídica, pois em determinados casos, apesar da solução prática para o caso ser a mesma em uma ou outra teoria, a solução jurídica poderá ser diferente.

Dentre as teorias jurídicas formuladas acerca do tema, existem três que se destacam: a teoria concepcionista, a teoria da nidação e a teoria do desenvolvimento do sistema nervoso central.

\section{TEORIA CONCEPCIONISTA}

\section{$1.1 \quad$ Conceito}

Para os defensores da teoria concepcionista, o marco inicial da vida humana é a concepção, ou seja, o momento em que o gameta masculino se funde com o gameta feminino, formando o zigoto, e neste ser unicelular, já estaria presente a vida humana.

Renata da Rocha esclarece ainda que:

A teoria concepcionista, considerando a primeira etapa do desenvolvimento embrionário humano, entende que o embrião possui um estatuto moral semelhante ao de um ser humano adulto, o que equivale a afirmar que a vida humana inicia-se, para os concepcionistas, com a fertilização do ovócito secundário pelo espermatozoide. A partir desse evento, o embrião já possui a condição plena de pessoa, compreendendo, essa condição a 
complexidade de valores inerentes ao ente em desenvolvimento. ${ }^{502}$

Como será exposto a seguir, seus adeptos procuram sustentar esta teoria, apresentando diversos argumentos, de cunho jurídico e científico, invocando normas em vigor, e de leis que já foram revogadas, como o código civil de 1916, como também normas de natureza constitucional e até internacional, para confirmarem a tese de que a vida começa na concepção e, tendo em vista que o direito à vida é um direito inviolável, a proteção a ela deve começar naquele exato momento.

\section{$1.2 \quad$ Argumentos científicos}

O principal argumento utilizado pelos defensores desta corrente para sustentá-la, é o fato de que o zigoto, a primeira célula formada a partir da fecundação, já contém toda a carga genética do ser que começou a ser formado. Para tal teoria, nesta fase, o corpo é composto por uma única célula, que sofrerá diversas divisões até alcançar o ser humano adulto $^{503}$. Nas palavras do professor Paulo Thompson Flores:

Inexiste dúvida de que, a partir da concepção e dos primeiros desdobramentos celulares já existe vida. $\mathrm{E}$ esta vida carrega, naquele, ainda informe, conglomerado de células, o código genético individual que fará daquele ser um integrante único do gênero humano, diferenciado, em maior ou menos grau, de todos os seus demais congêneres. ${ }^{504}$

\footnotetext{
${ }^{502}$ ROCHA, Renata direito à vida e as pesquisas com células-tronco: limites éticos e jurídicos. Rio de Janeiro: Elsevier, 2008. p. 75.

503 MARTINS, Ives Gandra da Silva (coordenação). Direito fundamental à vida. São Paulo:/ Centro de Extensão Universitária, 2005. p.222.

504 FLORES, Paulo Thompson Flores, apud MARTINS, Ives Gandra da Silva (coordenação). Direito fundamental à vida. São Paulo:/ Centro de Extensão Universitária, 2005. p.161.
} 
Com a mesma convicção, o professor Jérôme Leujene diz:

Não quero repetir o óbvio, mas, na verdade, a vida começa na fecundação. Quando os 23 cromossomos femininos se unem aos 23 cromossomos masculinos, todos os dados genéticos que definem o novo ser humano já estão presentes. A fecundação é o marco inicial da vida. ${ }^{505}$

Na mesma linha de pensamento:

A biologia confirma que as três funções do princípio vivificador (alma ou morfé) de todo ser humano estão presentes no zigoto, a partir da formação de seu núcleo de 46 cromossomos. Ditas funções são: $a$ função unitiva, a função motora e a envolvente. ${ }^{506}$

Outro argumento utilizado para a sustentação dessa corrente de pensamento é o fato de que, no processo de formação de um novo ser, a intervenção humana cessa na fecundação. Isso quer dizer que, focando nos casos de fertilização in vita, o homem e a mulher têm a opção de ter ou não a relação sexual, uma vez que ela acontece, ocasionando a fecundação, o processo se torna autônomo. Não é necessário que a mãe aloje o produto da concepção em seu útero, pois isso é feito automaticamente. Da mesma maneira, não é a mãe que irá coordenar o seu desenvolvimento, isto se dá, igualmente, de maneira automática. Nas palavras de Leslei Lester dos Anjos Magalhães "o zigoto é o executor de seu próprio programa genético". 507

\subsection{ARGUMENTOS JURÍDICOS}

\footnotetext{
505 LEUJENE, Jérôme, apud MAGALHÃES, Leslei Lester dos Anjos. O princípio da dignidade da pessoa humana e o direito à vida. São Paulo: Saraiva, 2012. p. 97.

506 MARTINS, Ives Gandra da Silva (coordenação). Direito fundamental à vida. São Paulo:/ Centro de Extensão Universitária, 2005. p.405.

${ }^{507}$ MAGALHÃES, Leslei Lester dos Anjos. O princípio da dignidade da pessoa humana e o direito à vida. São Paulo: Saraiva, 2012. p.98.
} 
Os defensores dessa teoria buscam respaldo jurídico, no atual Código Civil, no Código Civil de 1916, na Constituição Federal de 1988 e em tratados internacionais, como o Pacto de São José, conforme será mostrado a seguir.

O Código Civil de 2002, em seu art. $2^{\circ}$, preceitua que "A personalidade civil do homem começa do nascimento com vida; mas a lei põe a salvo desde a concepção os direitos do nascituro". Em linhas gerais, este artigo repete redação do art. $4^{\circ}$ do Código Civil de 1916. Ives Gandra da Silva Martins entende que a parte final do referido artigo, é uma demonstração de que o Código Civil adotou a teoria concepcionista ${ }^{508}$, visto que, não seria possível falar em "direitos do nascituro" sem reconhecer o próprio nascituro como um sujeito de direito, e não um objeto de direito. Desta maneira:

Atribuir direitos e deveres significa afirmar personalidade. Tanto a segunda parte do art. $2^{\circ}$, que é exemplificativo, como outras normas do Código reconhecem expressamente ao nascituro direitos e status (como o de filho, por exemplo) e não expectativas de direitos. (...). O nascimento com vida apenas consolida o direito patrimonial, aperfeiçoando-o. 509

Dito isso, ao analisar o artigo supracitado da legislação vigente, concluem os autores da referida obra que: "considerando a nãotaxatividade do art. $2^{\circ}$, a previsão expressa de direitos e status ao nascituro, bem como o conceito de personalidade, sustento que o Código Civil filia-se à corrente concepcionista". 510

Já no âmbito constitucional, é invocada a norma trazida pelo tão aclamado art. $5^{\circ}$, proclamando que o referido artigo protege a vida huma-

\footnotetext{
508 MARTINS, Ives Gandra da Silva (coordenação). Direito fundamental à vida. São Paulo:/ Centro de Extensão Universitária, 2005. p.24.

509 MACHADO, Antônio Cláudio da Costa (org.); CHINELLATO, Silmara Juny de Abreu (coor.): Código civil interpretado: artigo por artigo, parágrafo por parágrafo. Barueri - SP: Manole, 2008. p. 8.

510 MACHADO, Antônio Cláudio da Costa (org.); CHINELLATO, Silmara Juny de Abreu (coor.): Código civil interpretado: artigo por artigo, parágrafo por parágrafo. Barueri - SP: Manole, 2008. p. 8
} 
na de maneira geral, e que isso também incluiria vida intrauterina. $\mathrm{O}$ argumento em questão será rebatido em momento oportuno, mas de certa maneira foge um pouco da discussão em questão, visto que em nenhum momento foi, nem será, defendida a tese de que não há vida durante a gestação. A questão principal se dá em torno do ponto em que esta se inicia e, como já foi dito, uma vez reconhecida a vida humana, ela deverá ser protegida incondicionalmente.

Já no tocante ao Pacto de São José, a norma invocada pelos concepcionistas, se vê positivada no artigo quarto que preceitua que todos têm o direito de ter a sua vida respeitada e, em geral, essa proteção se inicia na concepção. Por se tratar de um tratado internacional que versa sobre direitos humanos, e que foi aprovado de acordo com os procedimentos do art. $5^{\circ}$, parágrafo $3^{\circ}$, da $\mathrm{CF}$, equivale a uma emenda constitucional.

Sendo assim, os defensores dessa tese invocam os aludidos dispositivos legais para sustentá-la, afirmando com convicção que, não só a ciência afirma que a vida começa na concepção, mas que também o nosso ordenamento jurídico a reconhece a partir do mesmo momento.

\subsection{Críticas}

É notório e indiscutível que o concepto é dotado de vida e, como tal, possui carga genética própria. O que se discute é se esta vida seria humana ou não. Mais uma vez é necessário questionar qual a essência do ser humano.

Se a vida biológica fosse equiparada à vida humana, seria necessário reconhecer a "vida humana" do espermatozoide. Alguns poderiam rebater este ponto, afirmando que o espermatozoide não possui a sua carga genética completa. Mas tão intrigante seria reconhecer a "vida humana" nos diversos tecidos do nosso corpo, que já possuem sua carga genética.

Seria necessário, nos casos de transplantes de órgãos, reconhecer a "vida humana" para um fígado que está sendo transplantado. Ora, caso o manuseador ou transportador deste órgão, por culpa ou dolo, acabar por inutilizá-lo, ou seja, deixá-lo "morrer" ou "matá-lo", ele deverá responder por crime próprio, mas não por homicídio, visto que o órgão em questão, apesar de possuir carga genética, não possui vida humana. 
Já no tocante ao fato do embrião se desenvolver sem o auxílio de sua mãe, é necessário reafirmar que esse é dotado de vida biológica, e como características de todos os seres vivos, ele se desenvolve sozinho. Desenvolver-se sem o auxilio de sua mãe, não o torna humano, pois este desenvolvimento se dá de igual modo nos demais animais e a eles não é conferido o status de ser humano.

Em relação aos argumentos jurídicos apresentados, o questionamento feito é em relação aos conflitos de normas conforme será demonstrado.

Os dois métodos contraceptivos mais utilizados e disseminados são o preservativo e o anticoncepcional. Porém, existe outro que, assim como os demais, são amplamente comercializados e até distribuídos pelo governo, para os que não possuem condições para comprá-lo: a chamada "pílula do dia seguinte", que para alguns é uma autêntica técnica abortiva. lhães:

Conforme consta na obra de Leslei Lester dos Anjos Maga-

As pílulas estroprogesterônicas são compostas por dois hormônios sintéticos, um estrógeno e um progestônico, que exercem efeitos contraceptivos pela inibição do desprendimento do óvulo, ao atuar no sistema hipotálamo-hipofisário, alterando a composição do muco cervical, impedindo a subida do espermatozoide em direção ao óvulo. Todavia, tem também como efeitos a alteração da sequência normal das modificações do endométrio uterino, fazendo com que, ainda que houvesse a fecundação, o embrião não tenha a possibilidade de se implantar no útero, e a modificação das Trompas de Falópio, impedindo a passagem do espermatozoide, mas também a descida do embrião para o útero. Como vemos, falhando a contracepção, o aborto é utilizado. ${ }^{511}$

Note que, essa última forma de atuação, uma vez que for reconhecida a vida do embrião logo na concepção, acaba por eliminar uma

511 SGRECCIA, Elio, apud MAGALHÃES, Leslei Lester dos Anjos. O princípio da dignidade da pessoa humana e o direito à vida. São Paulo: Saraiva, 2012. p.138. 
vida humana. A contradição se dá pelo fato de que, para os defensores desta teoria, nosso ordenamento adota a teoria concepcionista, mas permite que este tipo de medicamento seja vendido em farmácias, sendo utilizado até em programas governamentais.

Como pode a lei ressalvar os direitos do nascituro desde a concepção, como prevê o art. $2^{\circ}$ do atual Código Civil, e permitir que, com apenas uma pílula, como é o caso da "pílula do dia seguinte", ou por qualquer outro método, todos esses direitos sejam violados, inclusive o direito à vida?

Da mesma maneira, perante esta teoria, seriam abortivos diversos métodos tais como o RU486 e a vacina anti-hCG, que são verdadeiros métodos contragestatórios. ${ }^{512}$ Até o chamado anticoncepcional é considerado como abortivo. Na referida obra o autor afirma que:

A minipílula contém apenas progesterônicos, em quantidade mínima, devendo ser utilizada diariamente, o que causa, como os demais anticoncepcionais hormonais, a alteração do ciclo do endométrio e, consequentemente, o aborto, em virtude de possibilitar, frequentemente, a ovulação, devido à baixa taxa de progesterônicos, agindo como verdadeiros abortivo e, no entanto, sendo vendida ao público como anticoncepcional. ${ }^{513}$

O processo de fertilização in vitro será estudado em momento oportuno, mas também é um procedimento que, uma vez reconhecida a vida do embrião, se tornaria totalmente inviável, pois não seria digno manter um "ser humano" crio preservado, como ocorre com os embriões excedentes.

É possível que, ao analisar o art. $2^{\circ}$ do Código Civil, o art. $4^{\circ}$ do Pacto de São José, e demais dispositivos que são utilizados na defesa dessa teoria, chegue-se a conclusão de que o ordenamento jurídico brasileiro adotou a teoria concepcionista, porém, se for feita uma análise mais profunda, é possível constatar que inúmeras são as permissões dadas pelo ordenamento jurídico que entram em conflito com os ideais desta teoria,

512 Idem. p. 140.

513 Idem. p. 139. 
como os casos mencionados. Ressalta-se aqui a importância, para não dizer a necessidade, de se adotar uma das teorias, pois enquanto uma norma pende para uma das teorias, outra a afronta violentamente, gerando uma insegurança jurídica.

\section{TEORIA DA NIDAÇÃO}

\section{$2.1 \quad$ Conceito}

Para se entender bem o que seria a teoria da nidação, é necessário compreender o processo de reprodução humana. É notório que a união do gameta masculino com o gameta feminino, ou seja, a fecundação ocorre na chamada trompa de falópio. A trompa de falópio é uma cavidade, um tubo, que une os ovários da mulher ao útero. Uma vez ocorrida a fecundação, esse óvulo não pode permanecer ali, pois além de ser muito provável que ele "morra", é altamente arriscado para a mãe. Nesses casos ocorre a chamada gravidez ectópica, em especial, a gravidez tubária. Esse ovo deve se implantar no útero materno, pois somente no útero é que o embrião irá encontrar as condições necessárias para o seu desenvolvimento. O fenômeno conhecido como nidação é a fixação do produto da concepção no útero materno, a partir do qual, se iniciará o processo para a formação de todos os anexos necessários para o seu desenvolvimento ${ }^{514}$.

Para os defensores da teoria da nidação, somente seria possível reconhecer a vida de um embrião, depois que fosse superada essa etapa de seu desenvolvimento. Nas palavras de Cristiane Beuren Vasconcelos:

Esta teoria apregoa que somente a partir da nidação (fixação) do ovo no útero materno é que começa, de fato, a vida. Tendo em vista que esta fase começa em torno do sexto dia - quando começam a ocorrer as primeiras trocas materno-fetais - e termina entre o sétimo e o décimo segundo dia após a fecundação, pela doutrina da nidação do ovo, enquanto este

\footnotetext{
514 DOURADO, Roberto, apud SILVA, Camila Francis. O embrião humano e a sua
} utilização sob a ótica da dignidade da pessoa humana. Osasco: Unifieo, 2010. p. 31. 
estágio evolutivo não for atingido, existe tãosomente um amontoado de células, que constituiriam o alicerce do embrião.515

Sendo assim, a vida se iniciaria alguns dias após a concepção, e não no exato momento dessa, como apregoa a teoria concepcionista.

\subsection{Argumento científico}

Utiliza-se como principal argumento científico o fato de que até a nidação pode ocorrer a segmentação do indivíduo, como é o caso dos gêmeos monozigóticos, sendo que os defensores desta teoria acreditam que não seria possível se falar em ser humano antes de ser confirmada a sua unicidade. ${ }^{516}$

Pode-se utilizar como argumento também o fato de que não seria possível o desenvolvimento do embrião fora do útero materno, tanto que nos casos da reprodução artificial, fertilização in vitro, em que a fecundação ocorre fora do corpo da mulher, se o embrião não for introduzido no útero materno ele não irá se desenvolver.

E ao se analisar o corpo da mulher durante o processo de reprodução humana, é possível observar que, a mulher não é considerada grávida antes deste momento. O seu corpo ainda não se reconhece como grávida, não havendo a produção dos hormônios relacionados à gestação, nem nenhuma outra alteração de seu corpo. ${ }^{517}$

Assim, sob a ótica da ciência, os defensores dessa teoria apregoam que a mulher só é considerada grávida, e seu corpo só a reconhece como tal, após a implantação do zigoto no seu útero, e somente depois disso é que se pode reconhecê-lo como um ser humano.

\footnotetext{
515 VASCONCELOS, Cristiane Beuren. A proteção do ser humano in vitro na era da biotecnologia. São Paulo: Atlas, 2006. p. 35.

${ }^{516}$ MARTINEZ, Stella Maris, apud RIBAS, Ângela Mara Piekarski. O direito à vida sob uma ótica contemporânea. Âmbito Jurídico. Seção Revista Âmbito Jurídico. Disponível em: $<$ http://www.ambito-juridico.com.br/site/index.php?n link=revistaartigosleitura\&artigo_id=2986>. Acessado em: 25 março 2015.

517 ROCHA, Renata da. $\mathbf{O}$ direito à vida e as pesquisas com células-tronco: limites éticos e jurídicos. Rio de Janeiro: Elsevier, 2008. p. 80.
} 


\subsection{ARGUMENTOS JURÍDICOS}

O principal argumento jurídico utilizado pelos defensores dessa teoria é em relação ao tema do aborto. Aborto pode ser definido como sendo a interrupção da gestação, com a morte do feto. ${ }^{518}$ Aqui, gestação deve ser interpretada como tendo seu início com a implantação do concepto no útero materno, como já foi explicado. Nas palavras de Júlio Fabbrini Mirabete "aborto é a interrupção da vida intrauterina, com a destruição do produto da concepção."

Portanto, a partir das definições apresentadas é licito concluir que o Código Penal adota a teoria da nidação visto que, ao reconhecer o aborto como uma eliminação de vida intrauterina, a eliminação de vida extrauterina seria totalmente atípico.

Se for analisado o processo de reprodução humana natural, fertilização in vita, é possível se traçar uma linha temporal no qual em um primeiro momento ocorre a fecundação fora do útero, em um segundo momento se inicia a "jornada" do produto da concepção ao útero materno, e em um terceiro momento se dá a efetiva fixação deste na parede do útero materno (nidação). De acordo com o conceito de aborto apresentado, qualquer ato praticado contra o zigoto antes da terceira etapa, ou seja, antes da nidação, é atípico. Para os defensores dessa teoria, esta é a justificativa para a livre comercialização das chamadas "pílulas do dia seguinte", pois essas atuam, como já foi explicado, de várias maneiras para impedir a fecundação, mas caso ela ocorra, também evitam que o produto da concepção se fixe na parede do útero, ou seja, impedem que se conclua a nidação e, como já foi dito, antes desta etapa se concluir, para o Código Penal, não há o que se falar em aborto.

\section{$2.4 \quad$ Críticas}

A primeira crítica que se pode fazer a essa teoria, se dá com as já mencionadas gravidezes ectópicas; em outras palavras: trata-se de uma gravidez extrauterina. O produto da concepção, ao contrário do procedi-

\footnotetext{
518 DELMANTO, Celso et al. Código penal comentado. 6. Ed. atual. e ampl. Rio de Janeiro: Renovar, 2002. p. 268.

${ }^{519}$ MIRABETE, Júlio Fabbrini. Manual de direito penal: parte especial. Ed. $24^{\text {a }}$. São Paulo: Atlas, 2006. p. 62.
} 
mento comum, não se fixa no útero materno, mas acaba por se alojar em outras partes do corpo da mãe, como por exemplo, os ovários e as trompas de falópio.

Veja que, nestes casos, apesar de raramente essa gravidez venha a culminar no nascimento do concepto, há uma gravidez. O corpo da mulher se reconhece como grávida, mesmo sem que a nidação tenha ocorrido.

A outra crítica que é possível se fazer é o fato de que essa teoria se baseia no ambiente em que se encontra o zigoto, para fixar o marco inicial de sua vida. É indiscutível que o útero é o ambiente apto para se desenvolver um embrião, mas será que apenas o fato de estar em um ambiente favorável ao seu desenvolvimento argumento suficiente para se definir o início de sua vida?

Partindo da premissa de que o ambiente define a vida do ser humano, seria necessário afirmar que, enquanto o ribeirinho que vive cercado por água e alimento é um ser humano vivo, o etíope, e demais homens que vivem em ambientes totalmente hostis, em condições de vida absolutamente precárias, não o são. Seria necessário reconhecer que por viver em ambientes impróprios para se desenvolver, essas pessoas perderam a sua humanidade ou a tem reduzida.

Concluímos assim que, embora a nidação seja uma etapa necessária para o desenvolvimento do ser humano, ela não é suficiente para que se tenha uma nova vida, nem tampouco o marco inicial da vida humana.

\section{TEORIA DO DESENVOLVIMENTO DO SISTEMA NERVOSO CENTRAL}

\subsection{Conceito}

Para essa teoria, a vida humana somente seria possível com o cérebro humano. Ora, se a característica marcante da raça humana é justamente a capacidade de raciocinar, e essa somente se dá graças à evolução do nosso cérebro, seria lúcido concluir que a vida humana somente poderia se dar com as primeiras ligações nervosas.

Para Fernanda dos Santos Souza: 
Esta teoria sustenta como principal defensor o biólogo contemporâneo Jaques Monod, prêmio Nobel de Biologia em 1965, o qual defende que, por ser o homem um ser fundamentalmente consciente, não é possível admiti-lo como tal antes do quarto mês de gestação, quando se pode constatar, eletroencefalograficamente, a atividade dos sistema nervoso central diretamente relacionado à possibilidade de possuir consciência. ${ }^{520}$

Assim, para essa teoria, o que define a vida humana é o cérebro, e que antes dele, ela seria impossível.

\subsection{Argumentos científicos}

Como já foi verificado, para os defensores dessa teoria a vida se inicia com o cérebro, porém o que ocorre é que há uma divergência entre os defensores desta teoria sobre em qual momento da formação do cérebro se dá o marco inicial da vida.

Na obra supracitada, Fernanda dos Santos Souza defende que antes do quarto mês de gestação não seria possível reconhecer a vida humana no concepto, e que somente depois de verificados sinais de atividade cerebral, seria possível reconhecê-la com convicção.

Porem, para Luís Roberto Barroso:

Se a vida humana se extingue, para a legislação vigente, quando o sistema nervoso para de funcionar, o início da vida teria lugar apenas quando este se formasse, ou, pelo menos, começasse a se formar. $\mathrm{E}$ isso ocorre por volta do $14^{\circ}$ dia após a fecundação, com a formação da chamada placa neural. ${ }^{521}$

\footnotetext{
${ }^{520}$ SOUZA, Fernanda dos Santos, apud SILVA, Camila Francis. O embrião humano e a sua utilização sob a ótica da dignidade da pessoa humana. 2010. 100 f. Dissertação (Mestrado em Direito) - Centro Universitário Fieo de Osasco, Osasco, SP, 2010.

${ }^{521}$ BARROSO, Luís Roberto apud SOUZA, Priscila Boim de. Teorias do início da vida e lei de biossegurança. [s.n.t.]
} 
Veja que em ambas as obras os autores reconhecem que o início da vida humana se dá com o cérebro, porém, na primeira, a autora defende que a vida humana se dá apenas com o início das atividades cerebrais, que segundo ela se dá por volta do quarto mês de gestação, enquanto para este, a simples formação rudimentar do cérebro, que para ele se dá no $14^{\circ}$ dia após a concepção, já seria o marco inicial da vida humana.

\subsection{Argumentos jurídicos}

A teoria do desenvolvimento do sistema nervoso central tem como fundamento essencial a lei n. ${ }^{\circ} 9.434$, de 4 de fevereiro de 1997, que disciplina a remoção de órgãos e tecidos para fins de transplantes e terapias. Isto se dá, pois, no art. $3^{\circ}$ da referida lei, em que se normatiza a remoção de órgãos e tecidos post mortem para fins de doação. O texto legal diz que esta remoção somente é possível depois de ser feito um diagnóstico de morte encefálica.

O Conselho Regional de Medicina de Goiás diz que:

A Morte Encefálica (ME) é caracterizada pela perda completa e irreversível das funções encefálicas, definida pela cessação das atividades corticais e do tronco encefálico, resultando, portanto, na morte da pessoa. ${ }^{522}$

O referido dispositivo legal diz também que o diagnóstico de morte encefálica deve ser constatado mediante a utilização de critérios clínicos e tecnológicos definidos por resolução do Conselho Federal de Medicina, que foram trazidos pela Resolução n. ${ }^{0}$ 1.480/97 do CFM, que traz os procedimentos a serem observados na constatação da morte cerebral de um ser humano.

Portanto, para a referida lei, de maneira sucinta, se for diagnosticada a morte cerebral de uma pessoa, para o direito ela será considerada

\footnotetext{
522 OLIVEIRA, Cacilda Pedrosa de. CREMEGO. Competência do diagnóstico da morte encefálica. Goiânia: 2014. Disponível em: <http://www.cremego .cfm.org.br/index.php?option=com_content\&view=article \&id=27121:2015-03-12-23-0625\&catid=3>. Acessado em: 01 abril 2015.
} 
como morta. Fazendo-se uma análise jurídica da referida norma, tem-se que não há proteção à vida após a paralização das atividades do sistema nervoso central, justamente porque para a lei ela está morta. Sendo assim, se alguém atentar contra o corpo do de cujus irá responder não por figuras penais de proteção à vida e a integridade física do ser vivo, e sim às relativas a proteção de cadáveres.

E é partindo justamente desta premissa de que a vida humana se finda juntamente com as atividades cerebrais, é que os defensores dessa teoria afirmam que a vida humana se inicia, de igual modo, juntamente com o surgimento do cérebro.

Veja que, devidos aos inúmeros avanços das tecnologias voltadas à área, é possível a "manutenção", das funções biológicas do corpo de uma pessoa que teve a sua morte encefálica diagnosticada. Cita-se como exemplo o caso da americana Trisha Marshal, que estava grávida e, em 1993, teve a sua morte encefálica diagnosticada após um tiro na cabeça, mas o seu corpo foi mantido em funcionamento, a pedido da família, até o nascimento de seu filho, o que acabou por se concretizar. ${ }^{523}$

Ao observar este caso, se faz necessário reafirmar o fato de que é possível haver vida biológica em um corpo humano, e o ordenamento jurídico não reconhecer a vida humana neste. Do ponto de vista jurídico, da mesma maneira que ocorre com o corpo humano, que continua em funcionamento mesmo depois que a vida se esvaiu, o embrião antes da formação do cérebro não é dotado de vida humana, apenas de vida biológica. Não se devem misturar estes dois conceitos, pois a vida humana é algo único, complexo, e não puramente biológico.

Mais uma vez é de extrema importância frisar que este é um tema multidisciplinar que mexe com o que há de mais íntimo do ser humano, envolvendo questões filosóficas e religiosas, porém a análise feita no presente trabalho tem cunho puramente jurídico, analisando a legislação vigente e, a partir daí, chegar às conclusões sobre o início da vida jurídica, e esta por sua vez não se mistura com a vida biológica, como já foi comprovado. E de acordo com a legislação vigente relacionada ao tema, mais precisamente, a lei n. ${ }^{\circ}$ 9.434/97, que traz o conceito de morte, é possível extrair a premissa de que sem cérebro não há vida, e aplicando-

${ }^{523}$ MUTO, Eliza; NARLOCH, Leandro. Uma nova morte. Revista SUPERinteressante. São Paulo, v. 221. ed. Dez/2005. Disponível em: <http://super.abril.com.br/ciencia/novamorte-446150.shtml>. Acessado em: 02 abril 2015. 
a ao extremo oposto à morte, é lícito concluir que a vida se inicia com o cérebro, pois, como foi dito, não há vida sem cérebro.

Outro argumento que pode ser utilizado na sustentação da referida teoria é a sua consonância com os atuais julgados do Supremo Tribunal Federal acerca do tema, e que, vale ressaltar, é o órgão máximo do judiciário no tocante a matéria de cunho constitucional, como é o caso do direito à vida e o princípio da dignidade da pessoa humana.

Um destes julgados foi a Ação Direita de Inconstitucionalidade (ADI) 3.510. A referida ação tem por objeto a declaração da inconstitucionalidade do dispositivo que autoriza as pesquisas com células-tronco de embriões congelados no processo de fertilização in vitro. Mas, para que fique bem esclarecido o decorrer da ação e os argumentos utilizados para a defesa de sua sanidade constitucional ou não, é necessário compreender como se dá o processo de fertilização in vitro, o que são as células-tronco e o procedimento das pesquisas com células-tronco embrionárias.

A fertilização in vitro (FIV) é um procedimento intimamente ligado com as teorias do início da vida, pois se trata de um procedimento artificial de concepção, e dependendo da teoria adotada, mesmo que de maneira não natural, já será um ser dotado de vida humana, gozando, portanto, de toda a proteção constitucional já elencada no capítulo anterior.

Outra ligação íntima do processo de fertilização in vitro com o tema do presente trabalho, é no que diz respeito às pesquisas com célulastronco embrionárias, uma vez que os embriões utilizados nestas pesquisas foram obtidos através daquele procedimento.

A técnica de fertilização in vitro consiste, basicamente, em coletar os gametas, tanto os femininos como os masculinos, e fecundá-los em um ambiente laboratorial, ou seja, "in vitro", ao contrário do processo natural, no qual a fertilização é feita "in vita", e depois de realizado esse procedimento, o produto da fertilização será transferido para o útero materno, dando continuidade ao processo natural da gestação. ${ }^{524}$

De acordo com os ensinamentos de Maria Helena Machado, a Fertilização In Vitro apresenta diversas etapas, vale dizer: indução da

524 DIFERENÇAS ENTRE INSEMINAÇÃO ARTIFICIAL E FERTILIZAÇÃO IN VITRO. Revista SUPERinteressante. São Paulo, v. 087. ed. Dez/1994. Disponível em: <http://super.abril.com.br/saude/diferencas-inseminacao-artificial-fertilizacao-in-vitro441060.shtml>. Acessado em: 02 abril 2015. 
ovulação, punção folicular e cultura de óvulos, coleta e preparação do esperma e inseminação e cultura dos embriões. ${ }^{525}$

Dentre os embriões produzidos, nem todos que são colocados de plano no útero materno, sendo que apenas alguns terminam o procedimento. Os excedentes são, em um primeiro momento, crio preservados (congelados). Isto é justificado nos casos em que a primeira tentativa de implantação do embrião no útero da mulher se mostrar infrutífera. Nesta ocasião, o médico terá "material" suficiente para se tentar uma segunda, ou quantas tentativas forem possíveis ou necessárias. Mesmo que a primeira tentativa seja bem sucedida, esta criopreservação também se torna útil, nos casos em que, passado algum tempo, o casal queira ter mais um ou alguns filhos, sem ter que transcorrer todo o procedimento supracitado, que além de caro, se mostra penoso para os pais, principalmente para a mãe que deve se submeter a todo um tratamento hormonal. ${ }^{526}$

Este armazenamento é feito com a submersão dos embriões em recipientes que contenham nitrogênio líquido, ou seja, os embriões são armazenados em temperaturas em torno de $-196{ }^{\circ} \mathrm{C}$ (cento e noventa e seis graus Celsius negativos). ${ }^{527}$

Uma vez que os doadores dos gametas utilizados na fertilização (casal que busca a gestação) decidam que não querem ter mais filhos, surge mais um grande problema: o que fazer com os embriões excedentes?

Diante dessa situação, os doadores dos gametas podem dar 4 (quatro) destinos aos embriões excedentes que se encontram crio preservados:

O primeiro destino é a doação para adoção, no qual estes embriões serão mantidos congelados até o aparecimento de um casal que tenha interesse em implantá-los, seja por impossibilidade de gerar os seus próprios embriões, como, por exemplo, o homem que é incapaz de produ-

\footnotetext{
${ }^{525}$ MACHADO, Maria Helena. Reprodução humana assistida: aspectos éticos e jurídicos. Curitiba: Juruá, 2006. p. 41.

526 MORAES, Leandro. Veja, passo a passo, como é um tratamento de fertilização in vitro. [s.l.]. [s.n.]. 2013. Disponível em: <http://noticias.uol. com.br/saude/album/2013/05/09/veja-passo-a-passo-como-e-um-tratamento-defertilizacao-in-vitro.htm\#fotoNav=23>. Acessado em: 06 abril 2015.

527 AYERS, Nathalie. Criopreservação: uma forma de preservar a fertilidade. [s.n.t.]. Disponível em: <http://www.minhavida.com.br/familia/tudo-sobre/16593 -criopreservacao-uma-forma-de-preservar-a-fertilidade>.
} 
zir os seus próprios espermatozoides, ou por qualquer outra motivação, como os casais que querem evitar os incômodos gerados pelas primeiras etapas da FIV. ${ }^{528}$

A segunda possibilidade é a destruição. Nessa hipótese, o embrião congelado poderá ser descartado. Nesses casos para se prosseguir devem ser constatadas algumas exigências. Esta hipótese divide a opinião de diversos especialistas, juristas, filósofos, entre outros. Acerca desta possibilidade, muitas são as dúvidas e poucas são as respostas e menor ainda o grau de segurança das mesmas, até mesmo se há, de fato, a possibilidade de destruí-los, ante a Resolução 1.358/92.

O terceiro destino possível para um embrião que se encontra crio preservado é assim permanecer por tempo indefinido. Muitos casais, mesmo depois de terem decido não aumentar a sua prole, decidem não destruir nem doar os embriões restantes, nem para outro casal nem para um laboratório para pesquisas. A maioria alega, principalmente por razões de crença religiosa, que esses embriões gerados são filhos deles assim como os demais que foram introduzidos e já nasceram. Assim, por assimilar os embriões com os seus filhos nascidos, destruir ou doar os primeiros, seria como ordenar a morte ou abandonar os segundos. E diante desta incapacidade de se desvincular dos embriões crio preservados, eles preferem mantê-los assim por tempo indeterminado. Não há previsão legal limitando o tempo em que se pode manter um embrião crio preservado, assim, essa situação pode se perpetuar ao longo dos anos.

A quarta e última possibilidade que se tem para um embrião que está crio preservado, e que os pais não têm interesse de gerar novos filhos, é a doação para centros de pesquisas. Essa possibilidade vem gerando muita polêmica, pois a pesquisa que está em evidência, em se tratando de embriões humanos, é a pesquisa com células tronco embrionárias que, como será constatado adiante, para a coleta destas células, é necessário a destruição destes embriões. Esta possibilidade encontra previsão legal no art. $5^{\circ}$ da Lei n. ${ }^{\circ} 11.105$ de 24 de março de 2005, conhecida como Lei da Biossegurança.

Como já foi exposto, a teoria concepcionista apregoa exatamente que a vida se inicia na concepção e, uma vez que esta teoria for adota-

\footnotetext{
528 DAMASIO, Carolina Regina Oliveira. Fertilização in vitro e o descarte dos embriões excedentes. 2007. 106 f. Monografia (bacharel em Direito) - Faculdade de Direito de Presidente Prudente/SP, Prudente, SP. 2010.
} 
da, a destruição destes embriões acarretaria a eliminação de uma vida humana, logo, será cometido um crime contra a vida.

Porém, a relevância da adoção de uma destas teorias já pode ser verificada no próprio processo de Fertilização In Vitro, e não só apenas nas pesquisas com estes embriões.

Como já explicado, depois de superadas algumas etapas dos procedimentos da fertilização in vitro, haverá a fertilização dos gametas coletados, e consequentemente, serão formados os embriões. Dentre estes, alguns serão transferidos para o útero materno, para que lá se desenvolvam, e outros serão congelados. Levando em consideração a tese trazida pela referida teoria, de que o embrião já é um ser humano vivo, esse congelamento não seria totalmente incompatível com o direito à vida e o princípio da dignidade da pessoa humana?

Se for aceita esta teoria, não só as pesquisas com células tronco devem ser proibidas, como também a FIV, pelo menos da maneira como são feitos hoje, pois ao se armazenar os embriões em nitrogênio líquido, eles estão mantendo "seres humanos" em uma espécie de "crio prisão". Seria digno manter um "ser humano" congelado? Uma vez adotada esta teoria, é possível afirmar, categoricamente, que não, pois isto seria reduzir o "homem" à condição de objeto.

Ao analisar este ponto, pode-se verificar, mais uma vez, a importância e a necessidade de se adotar uma das aludidas teorias, pois, como explicado, para a teoria concepcionista tanto a FIV como as pesquisas com células-tronco embrionárias são totalmente inconstitucionais, podendo ser qualificadas como crimes; já para as teorias da nidação e do desenvolvimento do sistema nervoso central, o fato é totalmente constitucional e atípico, visto que o embrião, na atual situação em que se encontra, não possui vida humana. Não seriam apenas juridicamente corretos estes procedimentos, como também desempenhariam um papel importantíssimo no âmbito social, visto que eles buscam sanar algumas das maiores aflições dos seres humanos, seja revertendo a incapacidade de reprodução de alguns, ou curando doenças terríveis, como as já mencionadas.

As pesquisas com células-tronco embrionárias é um tema que está em evidência, gerando muita polêmica, sendo consideradas por muitos como uma prática que atenta contra o direito à vida, e a controvérsia é tamanha que, como já foi dito, a questão chegou até a chegar ao Supremo Tribunal Federal. Mas antes de se analisar o julgado sobre este tema, é 
necessário que se conheça um pouco sobre tais pesquisas, assim como as próprias células tronco e o seu potencial.

Depois de ocorrida a fecundação, haverá a formação de uma nova célula, que ao longo dos primeiros dias, irá se dividir inúmeras vezes formando uma grande quantidade de células. A partir de determinado ponto, por volta do quinto dia após a fecundação, estas células-tronco geradas começarão a apresentar características próprias, uma se diferenciando da outra, sendo verificado aqui certo grau de especificidade, e continuarão a se dividir e a originar novas células com tais características, formando assim os mais variados tecidos que compõem o corpo humano. E é por causa desta capacidade das células-tronco de se transformar em várias células do corpo humano é que as pesquisas na área são tão buscadas. ${ }^{529}$

Uma célula-tronco embrionária pode se transformar em uma célula muscular assim como em uma que se encontra nos tecidos ósseos, ao contrário do que ocorre com as demais células, uma vez que células musculares produzem apenas outras com a mesma função, as células-tronco pode se "especializar" em qualquer célula encontrada no corpo humano.

$O$ grande entrave no tocante às pesquisas com células-tronco gira em torno das células-tronco embrionárias, pois a coleta destas acarreta a destruição do embrião, o que para alguns, vale dizer os concepcionistas, se trata de eliminação de uma vida humana.

Vale ressaltar o fato de que os expositores pertencentes ao grupo de cientistas que defendem a inconstitucionalidade do art. $5^{\circ}$, e seus parágrafos, da Lei da Biossegurança de maneiras e por motivos diferentes, afirmaram que a vida começa na concepção, e que direcionar estes embriões excedentes, que se encontram congelados, para pesquisas seria incompatível com o Direito à Vida e com o Principio da Dignidade da Pessoa Humana.

Nesta linha hipotética, em que seria reconhecida a vida humana do embrião, proibindo-se assim a criopreservação de novos embriões humanos, ainda assim haveria um grande impasse: qual o melhor destino para os embriões extranumerários já congelados? No final da audiência

${ }^{529}$ BRASIL. Supremo Tribunal Federal. Ação direta de inconstitucionalidade no $3510 / \mathrm{DF}$ - Distrito Federal. Relator: Ministro Ayres Britto. Pesquisa de Jurisprudência, Acórdãos, 29 maio 2008. Disponível em: <http://www.stf.jus.br /portal/jurisprudencia/pesquisarJurisprudencia.asp>. Acesso em: 10 agosto 2015. 
pública realizada para o julgamento da ADIN 3.150, o relator desta levantou algumas questões acerca do tema, para que os representantes de cada grupo pudessem responder, e uma destas questões foi justamente esta.

Nas palavras da Dr. ${ }^{a}$ Lygia Pereira:

Nos aceitamos a geração destes embriões no dia em que aceitamos as técnicas de reprodução assistida, em particular a fertilização in vitro. É inerente destas técnicas, com a tecnologia que a gente tem hoje, a produção de um número excedente, ou pelo menos descontrolado, de embriões. ${ }^{530}$

Os destinos possíveis para um embrião que se encontra congelado se resumem a: implantação no útero da mulher que forneceu, juntamente com o seu marido, os gametas; doação, para que um casal terceiro possa implantar o embrião; destruição, destino este que o embrião seria "assassinado" por ato humano, ou deixado em ambiente para que este "morra naturalmente"; doação para pesquisas com células-tronco embrionárias, nos quais a obtenção destas células acarretam na destruição destes embriões; e por fim, o congelamento eterno, ou indeterminado. ${ }^{531}$

Levando em conta a quantidade de embriões que se encontram nesta situação, centenas de milhares ${ }^{532}$, e que a maioria dos casos os pais já não têm interesse de ter mais filhos, quando não simplesmente os abandonam, o primeiro destino já se tornaria muito improvável. Restam outras quatro alternativas, sendo que apenas a primeira não afrontaria os aclamados preceitos constitucionais. Em primeiro lugar, este destino, apesar de ser muito bonito na teoria, na prática não acontece com tanta frequência, sendo mais procurado por casais que não conseguem produzir os seus próprios embriões. Isto, na prática representa menos de $2 \%$, ou

${ }^{530}$ BRASIL. Supremo Tribunal Federal. Ação direta de inconstitucionalidade $n^{\circ}$ 3510/DF - Distrito Federal. Relator: Ministro Ayres Britto. Pesquisa de Jurisprudência, Acórdãos, 29 maio 2008. Disponível em: < http://www.stf.jus.br/portal/ jurisprudencia/pesquisarJurisprudencia.asp >. Acesso em: 10 agosto 2015.

${ }^{531}$ BRASIL. Supremo Tribunal Federal. Ação direta de inconstitucionalidade $n^{\circ}$ 3510/DF - Distrito Federal. Relator: Ministro Ayres Britto. Pesquisa de Jurisprudência, Acórdãos, 29 maio 2008. Disponível em: < http://www.stf.jus.br/portal/jurispruden cia/pesquisarJurisprudencia.asp>. Acesso em: 10 agosto 2015.

${ }^{532}$ Ibidem. 
seja, mais de $98 \%$ dos embriões excedentes não são $\operatorname{adotados}^{533}$. Qualquer uma das outras três alternativas seria "desumana", pois ou acarretam a destruição do embrião, ou o seu congelamento.

Respondendo a questão supracitada, a expositora Lenise Aparecida Martins Garcia respondeu da seguinte maneira: "Para mim é como perguntar qual o jeito ético de dividir o fruto de um roubo.” E logo em seguida completa: “[...] uma vez que eu já rompi o marco ético, eu já não tenho referência. $\mathrm{O}$ marco ético é: eles nunca deveriam ter sido congelados." 534

Depois de três anos sob análise, no dia vinte e nove de maio de dois mil e oito, o Supremo Tribunal Federal julgou a tão polêmica Ação Direta de Inconstitucionalidade três mil quinhentos e dez (ADI 3.510), conhecida como ADI das Células Tronco Embrionárias.

Em uma audiência muito acalorada, o STF acabou por decidir pela sanidade constitucional do art. $5^{\circ}$, e parágrafos, da lei 11.105/2005 (Lei da Biossegurança). Pela vantagem mínima de 6 votos contra 5, a ADI 3.510 foi julgada improcedente.

Outro julgado do STF que tem íntima relação com o tema é a ADPF 54. A Arguição de Descumprimento de Preceito Fundamental 54 foi proposta perante o Supremo Tribunal Federal no dia 17 de junho de 2004, pelo Conselho Nacional dos Trabalhadores na Saúde (CNTS), objetivando que o Tribunal se pronunciasse de forma a impossibilitar o enquadramento da interrupção terapêutica de gestação nos casos de anencefalia, nos crimes tipificados nos arts. 124 e 126 do CP. Desta maneira, uma vez constatados a malformação fetal da anencefalia, estaria autorizado o procedimento para a interrupção desta gestação.

Anencefalia é definida como a "má-formação fetal congênita por defeito do fechamento do tubo neural durante a gestação, de modo que o feto não apresenta os hemisférios cerebrais e o córtex, havendo apenas resíduo do tronco encefálico". 535

${ }^{533}$ BRASIL. Supremo Tribunal Federal. Ação direta de inconstitucionalidade $\mathrm{n}^{\circ}$ 3510/DF - Distrito Federal. Relator: Ministro Ayres Britto. Pesquisa de Jurisprudência, Acórdãos, 29 maio 2008. Disponível em: < http://www.stf.jus.br/portal/jurispruden cia/pesquisarJurisprudencia.asp>. Acesso em: 10 agosto 2015.

${ }^{534}$ Ibidem.

${ }^{535}$ BRASIL. Supremo Tribunal Federal. Arguição de descumprimento de preceito fundamental no 54/DF - Distrito Federal. Relator: Ministro Marco Aurélio. Pesquisa de Juris- 
Para sustentar tal pedido, foram invocados, basicamente, os preceitos da dignidade da pessoa humana, o princípio da liberdade e autonomia da vontade e o direito à saúde.

A requerente arguiu que a anencefalia é uma patologia que impossibilita a vida extrauterina, e afirma que obrigar a gestante a prolongar a gestação até o final, seria algo equiparado à tortura. Afirmou também que, uma vez que não há vida extrauterina em potencial, não há violação de nenhum dos bens tutelados pelos arts. 124 a 128, do CP, que tratam do crime de aborto.

Uma vez que ficou bem claro o que é a anencefalia, se faz necessário lembrar que no Brasil o aborto eugênico, aquele o qual é praticado sob a justificativa de que o feto é portador de defeitos físicos ou mentais, ou de alguma anomalia ${ }^{536}$, é terminantemente proibido. Ora, como pode este ser proibido e aquele, após este julgado do STF, ser autorizado?

Como será exposto, a anencefalia é incompatível com a vida, tanto que não é utilizado o termo "aborto" para os casos de anencefalia. Como já dito, aborto é eliminação de vida intrauterina, e nos casos de anencefalia, não há vida. Por isso, a expressão interrupção terapêutica da gestação é mais adequada do que "aborto".

Veja, neste ponto, que o crime de aborto tem como objeto jurídico a "vida" do feto e, nos casos de aborto provocados por terceiros, a incolumidade física e psíquica da mulher. ${ }^{537}$ Caso seja a vontade da mãe, o único bem tutelado seria a "vida" do produto da concepção, e nestes casos esta não existe, não havendo motivo para a manutenção desta prática como crime, nestes casos.

Nesta mesma linha de raciocínio está o relator Marco Aurélio que diz:

Aborto é crime contra a vida. Tutela-se a vida em potencial. No caso do anencéfalo, não existe vida possível. O feto anencéfalo é biologicamente vivo, por ser formado por células vivas, e juridicamente

prudência, Acórdãos, 09 abril 2012. Disponível em: <http://www.stf. jus.br/portal/jurisprudencia/pesquisarJurisprudencia.asp>. Acesso em: 10 agosto 2015.

${ }^{536}$ MASSON, Cleber. Código penal comentado. 2. ed. rev. atual. e ampl. Rio de Janeiro: Forense. 2014. p. 555

537 JESUS, Damásio E. de. Código penal anotado: Damásio E. de Jesus. 17 ed. atual. São Paulo: Saraiva, 2005. pg. 431 
morto, não gozando de proteção estatal. [...] $\mathrm{O}$ anencéfalo jamais se tornará uma pessoa. Em síntese, não se cuida de vida em potencial, mas de morte segura. Anencefalia é incompatível com a vida. ${ }^{538}$

Outro ponto importante é o explorado pelo advogado Luís Roberto Barroso, que disse que "No feto anencefálico, o cérebro sequer começa a funcionar. Então não há vida em sentido técnico e jurídico. De aborto não se trata.". 539 Sob este aspecto é possível levantar a seguinte questão: partindo do pressuposto de que a morte é decretada com o encerramento das atividades cerebrais, em que momento deve ser decretada o encerramento de algo que nunca funcionou, e em alguns casos nem se quer existiu?

Sobre esta questão, mais uma vez, se faz necessário repetir as sábias palavras proferidas pelo relator:

Ora, inexistindo potencialidade para tornar-se pessoa humana, não surge justificativa para a tutela jurídico-penal, com maior razão quando eventual tutela esvarra em direitos fundamentais da mulher, como se verá adiante. Enfim, cumpre tomar de empréstimo o conceito jurídico de morte cerebral previsto na Lei 9.434/1997, para concluir ser de todo impróprio falar em direito à vida intrauterina ou extrauterina do anencéfalo, o qual é um natimorto cerebral..$^{540}$

Veja que, pelo conceito de morte aplicável a todos, este concepto não tem vida. Aqui é possível se fazer um paralelo entre o anencéfalo e a pessoa que se encontra em estado de morte cerebral, mas é mantida viva com a ajuda de aparelhos. A gestante exerce para o anencéfalo a mesma função que os aparelhos para quem teve a sua morte cerebral decretada. $\mathrm{O}$

\footnotetext{
538 BRASIL. Supremo Tribunal Federal. Arguição de descumprimento de preceito fundamental $n^{\circ}$ 54/DF - Distrito Federal. Relator: Ministro Marco Aurélio. Pesquisa de Jurisprudência, Acórdãos, 09 abril 2012. Disponível em: < http://www.stf.jus. br/portal/jurisprudencia/pesquisarJurisprudencia.asp>. Acesso em: 10 agosto 2015.

${ }^{539}$ Ibidem.

${ }^{540}$ Ibidem.
} 
anencéfalo depende da gestante para manter o seu corpo funcionando, assim como o outro depende dos aparelhos, e uma vez rompida esta ligação, ambos os corpos irão morrer, mas se a pessoa que teve morte cerebral está inegavelmente morta, não seria o mesmo o que ocorre com o anencéfalo?

Veja que, mesmo que ao nascer sejam colocados aparelhos que permitam que o seu corpo continue a funcionar, não há atividade cerebral, logo, a sua situação se equipara ao homem adulto que se encontra em situação de morte cerebral. Em relação a este homem não há discussão: para o direito, ele não tem mais vida humana, apenas biológica, e o mesmo acontecerá com o anencéfalo. E ao nascer, sua situação permanecerá idêntica, apenas deixará de ser dependente da mãe e passará a ser dependente de aparelhos, logo, é possível concluir que mesmo dentro do ventre materno, este concepto já estava morto, ou melhor, nunca veio a ter vida, pois não desenvolveu cérebro.

Não resta alternativa senão a tomada pelo STF e entender que o anencéfalo não tem vida.

Observe que, o anencéfalo é um feto que, obviamente, superou os processos de concepção e nidação, e mesmo assim o STF não lhe reconheceu a vida pelo fato de não possuir cérebro. Sendo assim, é possível afirmar que antes do cérebro não é possível que haja vida humana, assim como foi constatado nos demais capítulos deste trabalho. Como já dito, estas etapas apenas garantem a sua vida biológica e propiciam o seu desenvolvimento, mas não lhe concedem vida humana.

\subsection{Críticas}

No que tange a esta teoria, a maior crítica que se faz é que ela confunde duas coisas totalmente opostas, vale dizer, o início e o fim da vida $^{541}$. Mas na verdade, não é bem isto que ocorre.

O que se faz é partir da análise dos preceitos legais trazidos para a decretação da morte é chegar a uma premissa. Depois, aplica-se esta no extremo oposto, no caso da morte, o início da vida.

\footnotetext{
${ }^{541}$ MAGALHÃES, Leslei Lester dos Anjos. O princípio da dignidade da pessoa humana e o direito à vida. São Paulo: Saraiva, 2012. p. 100.
} 
Ao notar que uma pessoa não possui mais atividades cerebrais, é possível, após diversos testes, declará-la como morta, ou seja, depois do fim das atividades cerebrais não há vida humana, mesmo que se tenha um corpo totalmente desenvolvido, carga genética completa e órgãos em funcionamento, ainda que com a ajuda de aparelhos, enfim, nada disso tem o condão para afastar o quadro de morte encefálica. Dito isso, é possível afirmar que depois do fim das atividades cerebrais não há vida humana, logo, antes dela também não.

Já foi comprovado diversas vezes ao longo deste trabalho que é possível que haja vida biológica em um corpo humano, sem que haja vida humana.

Desta maneira, não há o que se falar em misturar dois conceitos, mas sim através de um definir o outro. É o que ocorre, por exemplo, com a luz e a escuridão. Luz, segundo o dicionário Aurélio, pode ser definida como "radiação eletromagnética capaz de provocar sensação visual num observador normal" 542 . Já na definição de escuridão, o mesmo dicionário apresenta como uma de suas definições como simplesmente "falta de luz"543. Esta definição é tão simples quanto precisa, valendo-se de um, para definir o outro.

Sendo assim, não há confusão entre o que é morte e o que é início da vida, mas, como não há uma definição legal do que é vida e quando ela começa, deve-se analisar o que se tem, e no caso, o que se tem é o conceito legal de morte. Sendo assim, ao analisar o conceito trazido, observa-se que não é possível haver vida humana sem as atividades cerebrais. Ao aplicar-se esta afirmação no extremo oposto, chega-se à conclusão de que só se pode falar em início da vida humana com o desenvolvimento do cérebro. Sem cérebro, não há vida humana. E foi por este motivo que o anencéfalo chegou até a ser chamado de "natimorto cerebral"544, pois não possui vida humana por não ter um cérebro, e como já dito, esta ação restou julgada de modo a permitir a chamada "interrupção terapêuti-

\footnotetext{
542 FERREIRA, Aurélio Buarque de Holanda. Novo dicionário Aurélio da língua portuguesa. 4. ed. Curitiba: Positivo; 2009. p. 1237.

543 Idem. p. 797.

544 BRASIL. Supremo Tribunal Federal. Arguição de descumprimento de preceito fundamental no 54/DF - Distrito Federal. Relator: Ministro Marco Aurélio. Pesquisa de Jurisprudência, Acórdãos, 09 abril 2012. Disponível em: < http://www.stf.jus.br /portal/jurisprudencia/pesquisarJurisprudencia.asp>. Acesso em: 10 agosto 2015.
} 
ca da gestação" nos casos de anencefalia, e não o "aborto de anencéfalo" pois não há vida a ser eliminada.

\section{CONSIDERAÇÕES FINAIS}

Depois de todo o analisado, conclui-se que a vida humana começa com o desenvolvimento do sistema nervoso central. É da essência do ser humano o seu psiquismo, o seu pensar, o seu sentir, o seu ser. Não seria razoável aceitar que a vida humana, assim como a vida dos animais, possa ser resumida à vida biológica.

Desta maneira, antes de adquirir esta capacidade de desenvolver seu cérebro não é possível reconhecer vida humana em um corpo humano. Antes disso, este corpo é dotado de tão somente vida biológica. Não é possível que haja vida humana sem que se tenha um corpo humano, pois este é o receptáculo da vida. Porém, apenas o corpo também não indica que ali há vida humana.

Para defender a tese de que a vida se inicia com o desenvolvimento do sistema nervoso central, partiu-se da premissa de que há diferença entre a vida humana e a vida biológica em um corpo humano, e do conceito legal trazido para o seu oposto, a morte. Além disso, para confirmar a defesa da teoria defendida, procurou-se demonstrar que esta teoria está em consonância com dois julgados proferidos pelo Supremo Tribunal Federal.

A partir da definição de morte, trazida pela lei de transplante de órgãos, foi possível afirmar que não há vida humana, no que tange ao âmbito jurídico, após a cessação das atividades do sistema nervoso central. Por outro lado, seria lúcido afirmar que se não há vida depois da paralisação das atividades do sistema nervoso central, antes delas também não há vida humana. ${ }^{545}$

Diante disto, é possível se perguntar o que há antes, do início, e depois, do final, da vida humana, já que não se trata mais de vida humana. A resposta é simples: vida biológica em um corpo humano. Quando

\footnotetext{
545 BRASIL. Supremo Tribunal Federal. Arguição de descumprimento de preceito fundamental n ${ }^{\circ}$ 54/DF - Distrito Federal. Relator: Ministro Marco Aurélio. Pesquisa de Jurisprudência, Acórdãos, 09 abril 2012. Disponível em: < http://www.stf.jus.br/portal/j urisprudencia/pesquisarJurisprudencia.asp>. Acesso em: 10 agosto 2015.
} 
um corpo humano, depois da paralisação do sistema nervoso central, é mantido em funcionamento, tem-se ali uma vida puramente biológica, já que juridicamente falando, esta pessoa está morta, como o caso da Trisha Marshall ${ }^{546}$, como já foi citado.

O mesmo ocorre no extremo oposto. A partir da fecundação se inicia o processo de desenvolvimento do corpo humano, mas ainda não há vida humana: trata-se apenas de vida biológica em um corpo humano. Assim, até o desenvolvimento do cérebro não há vida humana.

Portanto, a vida humana se inicia com o desenvolvimento do sistema nervoso central, e com o início de suas funções, e termina com a paralisação das mesmas funções deste sistema.

Acerca do tema, o Supremo Tribunal Federal foi chamado para se pronunciar em duas ocasiões: na Ação Direta de Inconstitucionalidade 3.510 e na Arguição de Descumprimento de Preceito Fundamental 54. E ambos os julgados reforçam a tese aqui defendida.

A ADI 3.510 foi baseada na afirmação de que a vida humana se inicia com a fecundação. Logo, a proteção estatal deve se iniciar neste momento inicial, e portanto, as pesquisas com células tronco embrionárias, tema central desta ação, deveriam ser proibidas.

Não é razoável reconhecer a vida humana em um embrião, e autorizar pesquisas que acarretem a sua eliminação. Sendo assim, não só as pesquisas com células tronco embrionárias estariam comprometidas, como também a fertilização in vitro, pois, pelo menos atualmente, os embriões excedentes são congelados, e este procedimento de congelar "seres humanos vivos" não é compatível com o princípio máximo que é o da dignidade da pessoa humana.

Outro julgado marcante em relação ao tema foi a ADPF 54, que acabou por autorizar a interrupção terapêutica da gestação nos casos de anencefalia, ou, legalizou o "aborto" de anencéfalo.

Nesta ação foi autorizada a interrupção da gestação quando o feto for portador de uma má formação fetal chamada de anencefalia, ou

\footnotetext{
546 MUTO, Eliza; NARLOCH, Leandro. Uma nova morte. Revista SUPERinteressante. São Paulo, v. 221. ed. Dez/2005. Disponível em: <http://super.abril.com.br/ciencia/novamorte-446150.shtml>. Acessado em: 02 abril 2015.
} 
seja, quando o feto não possuir cérebro. A fundamentação básica foi a de que, assim como a teoria que sustento, sem cérebro a vida é inviável. ${ }^{547}$

Note que se trata de um feto fecundado e nidado, mas não the foi reconhecida vida humana, pelo fato de não possuir cérebro. $O$ produto da concepção se desenvolveu chegando a possuir o corpo praticamente idêntico ao de qualquer ser humano nesta fase de seu desenvolvimento. Mas somente o corpo desenvolvido não é o suficiente para que se tenha vida humana.

Esta ação em especial comprova de fato as duas afirmações feitas no início: é possível que haja vida biológica em um corpo humano, sem que se tenha vida humana, como acontece com os anencéfalos, que se desenvolvem, mas não são dotados de vida humana; e a vida humana está condicionada ao desenvolvimento do cérebro, pois o produto da concepção passou pelas mais diversas fases do seu desenvolvimento, mas o fato de não possuir cérebro não permite que ele seja qualificado como dotado de vida humana.

Diante de todo o exposto, é possível afirmar que a vida juridicamente relevante é a vida humana que se inicia com o desenvolvimento do cérebro e as suas primeiras atividades, e termina com paralisação do sistema nervoso central. Mas isso não irá me impedir de acariciar a barriga da minha futura esposa nos momentos iniciais da gestação de nosso filho, nem me impedirá de conversar com um ente querido que venha a sofrer de morte encefálica. Isto é devido às minhas crenças pessoais.

Mas, mesmo diante deste dualismo, é possível afirmar com convicção, por tudo o que já foi exposto, principalmente pela legislação vigente, e pelos julgados proferidos pelo Supremo Tribunal Federal, que a teoria que melhor define o início da vida humana, no âmbito jurídico, é a teoria do desenvolvimento do sistema nervoso central.

\section{REFERÊNCIAS BILIOGRÁFICAS}

\footnotetext{
${ }^{547}$ BRASIL. Supremo Tribunal Federal. Arguição de descumprimento de preceito fundamental no 54/DF - Distrito Federal. Relator: Ministro Marco Aurélio. Pesquisa de Jurisprudência, Acórdãos, 09 abril 2012. Disponível em: < http://www.stf.jus.b r/portal/jurisprudencia/pesquisarJurisprudencia.asp>. Acesso em: 10 agosto 2015.
} 
AYERS, Nathalie. Criopreservação: uma forma de preservar a fertilidade. [s.n.t.]. Disponível em: <http://www.minhavida.com.br/familia/tudo-sobre/16593criopreservacao-uma-forma-de-preservar-a-fertilidade>. Acessado em 30 de março 2015

BRASIL. Supremo Tribunal Federal. Ação direta de inconstitucionalidade $\mathrm{n}^{\circ}$ 3510/DF - Distrito Federal. Relator: Ministro Ayres Britto. Pesquisa de Jurisprudência, Acórdãos, 29 maio 2008. Disponível em: < http://www.stf.jus.br/portal/jurisprudencia/pesquisarJurisprudenc ia.asp>. Acesso em: 10 agosto 2015.

BRASIL. Supremo Tribunal Federal. Arguição de descumprimento de preceito fundamental $n^{\circ}$ 54/DF - Distrito Federal. Relator: Ministro Marco Aurélio. Pesquisa de Jurisprudência, Acórdãos, 09 abril 2012. Disponível

em: < http://www.stf.jus.br/portal/jurisprudencia/pesquisarJurisprudenc ia.asp>. Acesso em: 10 agosto 2015.

DAMASIO, Carolina Regina Oliveira. Fertilização in vitro e o descarte dos embriões excedentes. 2007. 106 f. Monografia (bacharel em Direito) - Faculdade de Direito de Presidente Prudente/SP, Prudente, SP. 2010.

DELMANTO, Celso et al. Código penal comentado. 6. Ed. atual. e ampl. Rio de Janeiro: Renovar, 2002.

DIFERENÇAS ENTRE INSEMINAÇÃO ARTIFICIAL E FERTILIZAÇÃO IN VITRO. Revista SUPERinteressante. São Paulo, v. 087. ed. Dez/1994. Disponível em: $<$ http://super.abril.com.br/saude/diferencas-inseminacao-artificialfertilizacao-in-vitro-441060.shtml>. Acessado em: 02 abril 2015.

FERREIRA, Aurélio Buarque de Holanda. Novo dicionário Aurélio da língua portuguesa. 4. ed. Curitiba: Positivo; 2009.

JESUS, Damásio E. de. Código penal anotado: Damásio E. de Jesus. 17 ed. atual. São Paulo: Saraiva, 2005.

MACHADO, Antônio Cláudio da Costa (org.); CHINELLATO, Silmara Juny de Abreu (coor.): Código civil interpretado: artigo por artigo, parágrafo por parágrafo. Barueri - SP: Manole, 2008.

MACHADO, Maria Helena. Reprodução humana assistida: aspectos éticos e jurídicos. Curitiba: Juruá, 2006.

MAGALHÃES, Leslei Lester dos Anjos. O princípio da dignidade da pessoa humana e o direito à vida. São Paulo: Saraiva, 2012. 
MARTINS, Ives Gandra da Silva (coordenação). Direito fundamental à vida. São Paulo: Quartier Latin/ Centro de Extensão Universitária, 2005.

MASSON, Cleber. Código penal comentado. 2. ed. rev. atual. e ampl. Rio de Janeiro: Forense. 2014.

MIRABETE, Júlio Fabbrini. Manual de direito penal: parte especial. Ed. 24a . São Paulo: Atlas, 2006.

MORAES, Leandro. Veja, passo a passo, como é um tratamento de fertilização in vitro. [s.1.]. [s.n.]. 2013. Disponível em: $<$ http://noticias.uol.com.br/saude/album/2013/05/09/veja-passo-apasso-como-e-um-tratamento-de-fertilizacao-invitro.htm\#fotoNav=23>. Acessado em: 06 abril 2015.

MUTO, Eliza; NARLOCH, Leandro. Uma nova morte. Revista SUPERinteressante. São Paulo, v. 221. ed. Dez/2005. Disponível em: <http://super.abril.com.br/ciencia/nova-morte-446150.shtml>. Acessado em: 02 abril 2015.

OLIVEIRA, Cacilda Pedrosa de. CREMEGO. Competência do diagnóstico da morte encefálica. Goiânia: 2014. Disponível em: $<$ http://www.cremego.cfm.org.br/index.php?option=com_content\& view=article \&id=27121:2015-03-12-23-06-25\&catid=3>.

Acessado em: 01 abril 2015.

RIBAS, Ângela Mara Piekarski. O direito à vida sob uma ótica contemporânea. Âmbito Jurídico. Seção Revista Âmbito Jurídico. Disponível em: <http://www.ambitojuridico.com.br/site/index.php?n_link=revista_artigos_leitura\&arti go_id=2986>. Acessado em: 25 março 2015.

ROCHA, Renata da. O direito à vida e as pesquisas com célulastronco: limites éticos e jurídicos. Rio de Janeiro: Elsevier, 2008.

SILVA, Camila Francis. O embrião humano e a sua utilização sob a ótica da dignidade da pessoa humana. 2010. $100 \mathrm{f}$. Dissertação (Mestrado em Direito) - Centro Universitário Fieo de Osasco, Osasco, SP, 2010.

SOUZA, Priscila Boim de. Teorias do início da vida e lei de biossegurança. [s.n.t.]

VASCONCELOS, Cristiane Beuren. A proteção do ser humano in vitro na era da biotecnologia. São Paulo: Atlas, 2006. 